\title{
Leishmania amazonensis infection impairs dendritic cell migration from the inflammatory site to the draining lymph node
}

\author{
Micely DR Hermida', Priscila G Doria', Angela MP Taguchi ${ }^{1}$, José $O$ Mengel $^{2,3}$ and Washington LC dos-Santos ${ }^{1 *}$
}

\begin{abstract}
Background: In vitro studies show that Leishmania infection decreases the adhesion of inflammatory phagocytes to connective tissue by a mechanism dependent on the modulation of integrin function. However, we know little about the influence of this reduction in leukocyte adhesion on parasite dissemination from the infection site.

Methods: In this work, we used a model of chronic peritonitis induced by thioglycollate to study the effect of $L$. amazonensis infection on the ability of inflammatory phagocyte populations to migrate from an inflammatory site to the draining lymph node. Uninfected or Leishmania-infected thioglycollate-elicited peritoneal exudate cells were transferred from C57BL/6 to BALB/C mice or from Ly5.1 $1^{+}$to Ly5.1- mice. The transferred cells were injected into the peritoneal cavity and tracked to the draining lymph node.

Results: Migrating cells corresponded to approximately $1 \%$ of the injected leukocytes. The proportion of migrating

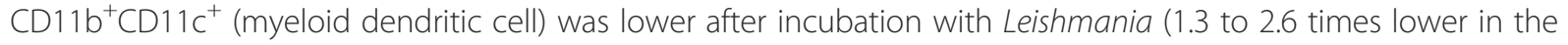
experiments using C57BL/6 to BALB/C animals and 2.7 to 3.4 times lower in the experiments using Ly5.1 $1^{+}$to Ly5.1- animals) than after leukocyte incubation with medium alone $(P<0.01)$. There was no consistent decrease in the migration of $\mathrm{CD} 11 \mathrm{~b}^{+} \mathrm{F} 4 / 80^{+}$(macrophage) or SSC ${ }^{\mathrm{hi}} \mathrm{GR}-1^{+}$(neutrophil) populations.

Conclusions: Coincubation with Leishmania changes the migratory pattern of dendritic cells in vivo. Such changes in dendritic cell migration may be associated with immunological events that maintain inflammation at the sites of infection.
\end{abstract}

Keywords: Leishmania, Leukocyte migration, Dendritic cell, Lymph node, Macrophage

\section{Background}

Leishmaniasis is initiated by the inoculation of Leishmania promastigotes into the skin of a susceptible host during the blood meal of an infected sand fly [1]. Thereafter, the parasite may remain at the inoculation site or disseminate in the host tissues. Permanence at the inflammation site and dissemination of the parasite may result in a wide spectrum of clinical manifestations that range from selfhealing skin ulcers to disfiguring mucosal lesions and fatal visceral leishmaniasis [1,2]. At the Leishmania inoculation site, various phagocytes have the potential to phagocytize and transport live amastigotes or killed parasites, which

\footnotetext{
* Correspondence: wluis@bahia.fiocruz.br

'Centro de Pesquisas Gonçalo Moniz, Oswaldo Cruz Foundation, Fiocruz, LPBI, Salvador, Brazil

Full list of author information is available at the end of the article
}

may also act as antigens, to the draining lymph node. These cells include dermal resident dendritic cells (DC), epidermal Langerhans cells, neutrophils and monocytes, which are released from the blood when the dermal capillary is disrupted and a reputed blood lake is formed [3-6]. Soon after, neutrophils and macrophages may still be recruited in response to local inflammatory stimuli that persist for 2-3 days [6]. Hence, a variety of mononuclear phagocytes have been shown to bear live amastigotes or molecules of dead parasites, both at the infection site and in the draining lymph node [4,7]. The ability of Langerhans cells or monocyte-derived DC to transport amastigotes from the skin to the lymph node has been demonstrated in various studies $[3,7]$. In progressive forms of cutaneous leishmaniasis, parasites and parasite molecules are continuously observed 
in the interior of the mononuclear phagocytes in the skin lesion and in the marginal sinus of the draining lymph nodes, suggesting that these phagocytes continuously transport parasite and parasite molecules [4]. At the inoculation site, amastigotes are maintained in the interior of the mononuclear phagocytes, and the immunoreactions elicited by these cells are associated with different types of nodular lesions or ulcers. We still know very little about the mechanisms controlling the ability of these cells containing live parasite or parasite fragments to remain in the infection site or to migrate to the draining lymph node. Evidence suggests that a number of phagocyte functions potentially associated with cell migration, such as intracellular PKC-dependent signaling pathways, cell adhesion and migration toward chemokine stimuli, are modulated during Leishmania infection [8-10]. In a previous work, we showed that coincubation with Leishmania impairs the adhesion of different mononuclear phagocytes to inflamed connective tissues and to connective matrix components in vitro and that this decrease in cell adherence correlates with the proportion of infected phagocytes and the parasite burden in the cell $[11,12]$.

Leukocyte exit from the inflammatory site towards the lymph node involves a sequence of steps, starting with the response of these cells to chemokines released by lymphatic endothelial cells [13-16]. In response to this stimulus, the leukocyte sequentially modulates the engagement of integrin interaction with connective tissue components in a directional way to reach the periphery of the lymphatic capillary $[17,18]$. Both adhesion and detachment are coordinated necessary steps in cell migration. Hence, the loss of adherence by phagocytes with a high Leishmania burden may impair the exit of these cells from the inflammatory site. The capability of Leishmania-infected cells to migrate or to remain in the infection site may be important for defining the characteristics and lesion distribution in leishmaniasis. For example, most of cutaneous leishmaniasi ulcer develops at the infection site, sometimes months after an initial papule. In other instances, after cure of cutaneous lesion metastatic mucocutaneos ulcers emerges.

In this study, we used the murine model of phagocyte migration in vivo described by Bellingan and collaborators [19] to examine whether the decrease in adhesion of phagocytes co-incubated with Leishmania to the connective tissue observed in vitro corresponded to changes in the migratory pattern of these cells in vivo. The model described by Bellingan and colleagues is designed for studying macrophage exit through the lymphatic system during the resolution of a thioglycollate-induced peritonitis and has characteristics that make it suitable for use in our study: (1) the thioglycollate-induced peritoneal exudate contains a variety of phagocytes, including neutrophils, macrophages and dendritic cell populations
[11,20,21]; (2) these cells are present in large numbers, thus allowing easy collection, in vitro manipulation and reinjection; (3) the adherence of the PEC to the connective tissue is also decreased after cultivation with Leishmania $[11,12]$; and (4) the emigration of mononuclear phagocytes from the peritoneal cavity to the lymph nodes observed in this in vivo migration system is dependent on VLA-4 [22], a molecule that we have shown to have altered function in Leishmania-infected phagocytes [8].

Bellingan and collaborators showed that the phagocyte exit from the peritoneal cavity to the parathymic lymph node is maximal in the $4^{\text {th }}$ day of thioglycollate peritonitis [19]. Hence, we chose this time point to study the effect of Leishmania infection on the migration of different populations of phagocytes to the draining lymph node. In this series of experiments we used Leishmania amazonensis. This species is endemic in parts of Brazil, usually associated with cutaneous lesions. However, some L. amazonensis strains have also been isolated from patients with visceral leishmaniasis [23]. Infections by this First, we performed a partial characterization of the phagocytes present in the peritoneal exudate and examined the capability of these different cell populations for phagocytizing Leishmania. Subsequently, we examined the change in the migration rate of cells incubated with Leishmania in conditions favoring the maximal decrease $(70 \%)$ in peritoneal exudate cell adhesion to connective matrix components observed in our studies in vitro $[11,12]$. The result of this study may contribute to the knowledge of the factors associated with the permanence of infected cells at the inoculation site or their dissemination to other host tissues.

\section{Methods}

\section{Animals}

Six- to eight-week-old BALB/c, C57BL/6 and C57BL/6 SJL mice (antigenic specificity Ly5.1) of both genders were obtained from the colony of the Gonçalo Moniz Research Center-FIOCRUZ (Salvador, Brazil). The animals were maintained under the controlled environmental conditions of humidity, temperature and a light-dark cycle, with commercial balanced mouse chow and water provided ad libitum. The animals were subjected to thioglycollate peritonitis and adoptive cell transfer via intraperitoneal injection (see below). At the end of the experiments, the animals were killed by lethal $\mathrm{CO}_{2}$ anesthesia, and the peritoneal exudate cells and parathymic lymph nodes were removed as described below. All experiments involving animals were conducted in accordance with Brazilian Federal Law on Animal Experimentation (Law 11794) [24] (http://www.planalto. gov.br/ccivil_03/_ato2007-2010/2008/lei/11794.htm). This study was approved by the Committee of Ethics in the Use of Animals of the CPqGM-FIOCRUZ (Ceua, licence N. 018/2009). 


\section{Phagocyte infections with Leishmania}

Leishmania amazonensis (Leila strain, MHOM/BR88/ BA-125) were grown in Schneider's insect medium (Sigma) containing $10 \% \mathrm{FBS}$ at $24^{\circ} \mathrm{C}$. Stationary phase promastigotes were washed three times in HBSS, suspended in complete RPMI, and incubated with the phagocytes. Control phagocytes were cultured in medium alone.

\section{Thioglycollate-induced peritonitis and leukocyte exit from} the peritoneal cavity to the draining lymph node

Peritonitis was induced in BALB/c, C57BL/6 and C57BL/6 SJL mice by injecting $3 \mathrm{ml}$ of a $3 \%$ (wt/vol) thioglycollate (Sigma-Aldrich Brasil Ltda, São Paulo Brazil) sterile solution. Three to four days after peritonitis induction, the PEC were collected by a standardized washing of the peritoneal cavity, performed twice with cold $\mathrm{Ca}^{2+}$ and $\mathrm{Mg}^{2+}$-free Hanks' balanced salt solution (HBSS, Sigma) containing $20 \mathrm{IU} / \mathrm{ml}$ heparin. The number of cells collected from each animal was estimated using a Neubauer chamber. Cell viability was assessed using the trypan blue exclusion technique, and cell populations were defined morphologically using cytospin preparations and by phenotyping using specific antibodies in flow cytometry. Parathymic lymph nodes were collected by dissection and were studied by flow cytometry.

\section{Rate of Leishmania phagocytosis by PEC}

To estimate the Leishmania phagocytosis rate by different phagocyte populations, parasites were labeled with PKH26 before coincubation with PEC. Briefly, $10^{8}$ parasites were suspended in $2 \mathrm{ml}$ of PBS, mixed with a $4 \mu \mathrm{M}$ PKH26 solution in $2 \mathrm{ml}$ of PBS and incubated for $5 \mathrm{~min}$ at room temperature in the dark under periodic agitation. Staining was terminated by the addition of $4 \mathrm{ml}$ of fetal bovine serum (FBS), incubation at $37^{\circ} \mathrm{C}$ for $30 \mathrm{~min}$ and washing three times in HBSS. At the end of $24 \mathrm{~h}$ of co-culture, the cells were washed and subjected to flow cytometry for identification of the mononuclear phagocyte populations positive for PKH26.

\section{Adoptive cell transfer-and-tracking experiments}

Thioglycollate peritonitis was induced in C57BL/6 (H-2 $\left.{ }^{\mathrm{b}}\right)$ mice. Three days after peritonitis induction, PEC were collected, washed twice in HBSS, suspended at $2 \times 10^{6}$ cell/mL in RPMI (Sigma) with $10 \%$ fetal bovine serum (FBS; Cultilab, Brazil), $60 \mathrm{~g} / \mathrm{ml}$ gentamicin and $2 \mathrm{mM}$ glutamine (complete RPMI) and cultured alone or with $2 \times 10^{7}$ stationary phase L. amazonensis promastigotes for $18-24 \mathrm{~h}$ in non-adherent polypropylene tubes at $37^{\circ} \mathrm{C}$ and $5 \% \mathrm{CO}_{2}$. The cells were washed and intraperitoneally transferred $\left(1 \times 10^{7}\right.$ cells $)$ to BALB/c $\left(\mathrm{H}-2^{\mathrm{d}}\right)$ mice. On the following day, the recipient animals were killed, and the PEC and parathymic lymph nodes were removed. The proportion of $\mathrm{H}-2^{\mathrm{b}+}(\mathrm{C} 57 \mathrm{BL} / 6)$ phagocytes of different populations present in the peritoneal cavity and in the draining lymph node was studied by flow cytometry.

To avoid the potential effect of the MHC mismatch between the mice strains, though the migration experiment was performed for only a short period, a similar set of experiments was performed using cell transfer-and-tracking experiments using C57BL/6 Ly5.1 ${ }^{+}$mice cell transfer to $\mathrm{C} 57 \mathrm{BL} / 6 \mathrm{Ly} 5.1^{-}$mice. Three days after peritonitis induction, PEC were collected and intraperitoneally transferred $\left(1 \times 10^{7}\right.$ cells) from C57BL/6 Ly5.1 ${ }^{+}$to $\mathrm{C} 57 \mathrm{BL} / 6$ Ly5. $1^{-}$recipient animals. After $24 \mathrm{~h}$, the PEC and parathymic lymph nodes were removed and processed for flow cytometric analysis.

\section{Cell preparation and flow cytometric analysis}

PEC were washed, counted and resuspended in FACS buffer containing an anti-Fc monoclonal antibody for 30 min on ice to block non-specific staining. Parathymic lymph nodes were cut into small fragments, digested with collagenase D $(0.5 \mathrm{mg} / \mathrm{ml}$, Boehringer-Mannheim, Germany) and diluted in RPMI 1640 medium supplemented with 3\% FBS and 0.1\% DNase I (Roche Diagnostic, Germany) for 10 minutes at $37^{\circ} \mathrm{C}$ with continuous agitation. Cell suspensions were filtered through gauze and washed twice in a phosphate-buffered saline (PBS) solution supplemented with 5\% FBS and 5 mM EDTA containing $5 \mathrm{mg} / \mathrm{ml}$ DNase I [7]. The cells were washed, counted and resuspended in FACS buffer for $30 \mathrm{~min}$ on ice to block non-specific staining.

The cells $\left(1-2 \times 10^{6} /\right.$ stain $)$ were incubated with fluorescein-conjugated antibodies (anti-CD11b (M1/70) and anti-I-A ${ }^{\mathrm{d}}$ (AMS-32.1) (BD-Pharmingen; San Jose, CA, USA); anti-F4/80 antigen (R1-2; Caltag; San Diego, CA, USA), phycoerythrin (PE) conjugates (anti-F4/80 (R1-2; Caltag, USA) and anti-H2 ${ }^{\mathrm{b}}$ (AF6-88.5, BD-Pharmingen; San Jose, CA, USA), and biotin-conjugated antibodies (anti-CD11c (HL3), CD45.1 (A20; BD-Pharmingen; San Jose, CA, USA) followed by streptavidin Cy-5 or phycoerythrin conjugate (BD-Pharmingen; San Jose, CA, USA). All antibody incubations were performed at $4^{\circ} \mathrm{C}$ for $20 \mathrm{~min}$ and were followed by three washes with FACS buffer. Unlabeled or isotype-matched stained cells were used as a control. Cells were analyzed on a FACScan flow cytometer using CellQuest software (Becton-Dickinson). The histograms and bitmaps of the distributions of cell populations were constructed using FlowJo Software (Tree Star, Inc.). Fifty thousand events were analyzed per sample [12]. The parameters for defining the cell populations have been described in previous studies [21,25-28]. In brief, cells positive for CD11b and antigens F4/80 were defined as macrophages, populations of cells with high granularity expressing GR-1 were defined as neutrophils, expression of CD11c ${ }^{\text {hi }}$ CD $11 b^{\text {hi }}$ were defined as myeloid dendritic cells. 


\section{Expression and analysis of the results}

The numerical data shown in the text, tables and graphs represent percentages of the total number of cells identified according to the defined parameters. To adjust the data obtained in different experiments, the proportion of migrating cells was expressed as the percentage of cells of a given population among the migrating leukocytes (injected into the peritoneal cavity and tracked to the lymph node) relative to the percentage of the same injected cell population remaining in the peritoneal cavity. The significance of the differences observed between the control and infected groups was tested using the paired Student's t-test. The threshold for statistical significance was set at $\mathrm{P}<0.05$. All experiments were performed independently a minimum of three times, using a minimum of six animals in each experimental group.

\section{Results}

Leishmania phagocytosis by different phagocyte populations present in the PEC

On the $4^{\text {th }}$ day after thioglycollate injection, the number of cells present in the peritoneal cavity was $1.7 \times 10^{7}$, approximately five times higher than that observed in control animals injected with saline $\left(0.3 \times 10^{7}\right.$ paired t test, $\mathrm{P}<0.0001$; data not shown). To investigate the efficiency of Leishmania phagocytosis by the different mononuclear phagocytes present in PEC, we co-cultivated PEC with PKH26-labeled promastigotes for $24 \mathrm{~h}$ and examined the phenotypes of PKH26-labeled leukocytes by flow cytometry. The phagocytosis rate was high $(68 \pm 31 \%$ to $77 \pm 22 \%$ ) among the $C D 11 b^{+}$populations (Table 1 ). However, this rate was substantially low in non-myeloid populations, including non-myeloid DC populations (CD11c ${ }^{+}$CD11b $^{-}, 33 \pm 13 \%$, Table 1 ).

Effect of $L$. amazonensis infection on the migration of different phagocyte populations from the inflammatory site to the draining lymph nodes C57BL/6 $\left(\mathrm{H}-2^{\mathrm{b}}\right)$ mouse peritoneal donor cells were cultivated overnight with medium alone (control) or with $L$. amazonensis (infected) and then injected into the peritoneal cavity of BALB/c mice (see Methods).

Table 1 Infection rate of different population of inflammatory mononuclear phagocytes coincubated in vitro with $L$. amazonensis

\begin{tabular}{lc}
\hline & Infection ratio (\%) \\
\hline $\mathrm{CD}_{11 c^{+}}$ & $72 \pm 17$ \\
$\mathrm{CD}_{11} \mathrm{c}^{+} \mathrm{CD} 11 \mathrm{~b}^{+}$ & $77 \pm 22$ \\
$\mathrm{CD}_{11 c^{+} \mathrm{CD} 11 b^{-}}$ & $33 \pm 13$ \\
$\mathrm{CD} 11 \mathrm{c}^{-} \mathrm{CD} 11 \mathrm{~b}^{+}$ & $68 \pm 31$ \\
$\mathrm{CD} 11 \mathrm{c}^{-} \mathrm{CD} 11 \mathrm{~b}^{-}$ & $30 \pm 19$ \\
\hline
\end{tabular}

Data are the mean (SEM) from seven experiments.
After $24 \mathrm{~h}$, the recipient mice injected with donor leukocytes cultivated with medium alone (control) had $13.1 \pm$ $3.8 \%$ of $\mathrm{H}^{\mathrm{b}+}(\mathrm{C} 57 \mathrm{BL} / 6)$ cells in the peritoneal cavity. Among these cells, $2.8 \pm 1.6 \%$ were neutrophils $\left(\mathrm{SSC}^{\text {hi }}\right.$ GR $\left.-1^{+}\right), 73.0 \pm 19.8 \%$ were macrophages $\left(\mathrm{CD} 11 \mathrm{~b}^{+} \mathrm{F} 4 / 80^{+}\right)$

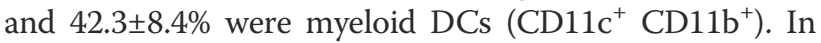
the lymph nodes (LNs) of these animals, $1.1 \pm 0.4 \%$ of the cells were $\mathrm{H}_{2}{ }^{\mathrm{b}+}$. Among these migrating cells, $3.8 \pm 0.7 \%$ were neutrophils $\left(\mathrm{SSC}^{\mathrm{hi}} \mathrm{GR}-1^{+}\right.$), $39.1 \pm 21.7 \%$ were macro-

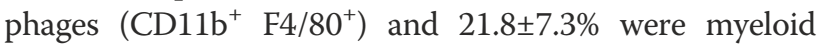
DCs $\left(C D 11 c^{+} \mathrm{CD}_{11 b^{+}}\right)$(Figure 1A).

In the group of animals injected with donor PEC cultivated with L. amazonensis (infected), the proportion of the $\mathrm{H} 2^{\mathrm{b}+}$ cells in the peritoneum was $11.4 \pm 6.8 \%$. Among these cells, $1.7 \pm 0.9 \%$ were neutrophils $\left(\mathrm{SSC}^{\text {hi }}\right.$ GR $\left.-1^{+}\right), 65.5 \pm 19.2 \%$ were macrophages $\left(\mathrm{CD} 11 \mathrm{~b}^{+} \mathrm{F} 4 / 80^{+}\right)$ and $39.3 \pm 4.9 \%$ were myeloid DC $\left(\mathrm{CD} 11 \mathrm{c}^{+} \mathrm{CD} 11 \mathrm{~b}^{+}\right)$. In the LNs, the proportion of migrating $\left(\mathrm{H}_{2}{ }^{\mathrm{b}+}\right)$ cells was $1.2 \pm 0.6 \%$. Among these cells, $4.4 \pm 2.8 \%$ were neutrophils $\left(\mathrm{SSC}^{\text {hi }} \mathrm{GR}-1^{+}\right), 34.7 \pm 21.8 \%$ were macrophages

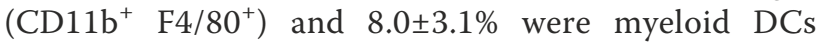
$\left(\mathrm{CD} 11 \mathrm{c}^{+} \mathrm{CD}_{11 \mathrm{~b}^{+}}\right)$(Figure 1A). Only the fraction of migrating myeloid DCs was consistently decreased in the draining LN after co-incubation with Leishmania (t Test paired test, $\mathrm{P}<0.01$, Figure $1 \mathrm{~B})$.

To confirm these data and avoid the potential effects of the MHC mismatch between mice strains, we used a Ly5.1 $1^{+}$cell transfer to Ly5.1- animals in the series of experiments shown in Figure 2. C57BL/6 SJL mouse Ly $5.1^{+}$peritoneal donor cells were cultivated overnight with medium alone (control) or with L. amazonensis (infected) and were then injected into the peritoneal cavity of C57BL/6 Ly 5.1 ${ }^{-}$mice (see Methods). After $24 \mathrm{~h}$, the recipient mice injected with donor leukocytes cultivated with medium alone (control) presented $10.7 \pm 1.6 \%$ of Ly $5.1^{+}$cells in the peritoneal cavity. Among these cells, $2.1 \pm 2.1 \%$ were neutrophils $\left(\mathrm{SSC}^{\text {hi }} \mathrm{GR}^{-1}{ }^{+}\right.$), $73.5 \pm 10.4 \%$

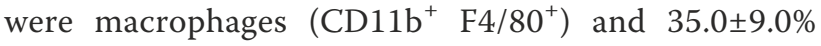

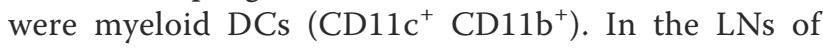
these animals, $1.1 \pm 0.4 \%$ of the cells were Ly $5.1^{+}$. Among these migrating cells, $3.4 \pm 1.8 \%$ were neutrophils $\left(\mathrm{SSC}^{\mathrm{hi}} \mathrm{GR}-1^{+}\right), 31.0 \pm 12.8 \%$ were macrophages $\left(\mathrm{CD} 11 \mathrm{~b}^{+} \mathrm{F} 4 / 80^{+}\right)$and $40.8 \pm 9.3 \%$ were myeloid DCs $\left(\mathrm{CD}_{11 \mathrm{c}^{+}} \mathrm{CD}_{11 \mathrm{~b}^{+}}\right.$) (Figure 2A).

In the group of animals injected with donor PEC cultivated with $L$. amazonensis (infected), the proportion of the Ly $5.1^{+}$cells in the peritoneum was $11.2 \pm 0.6 \%$. Among these cells, $2.1 \pm 2.3 \%$ were neutrophils (SSC ${ }^{\text {hi }}$ GR $\left.-1^{+}\right), 63.5 \pm 29.1 \%$ were macrophages $\left(\mathrm{CD} 11 \mathrm{~b}^{+} \mathrm{F} 4 / 80^{+}\right)$ and $46.7 \pm 28.7 \%$ were myeloid DCs $\left(\mathrm{CD} 11 \mathrm{c}^{+} \mathrm{CD} 11 \mathrm{~b}^{+}\right)$. In the LNs, the proportion of migrating (Ly 5.1+) cells was $1.2 \pm 0.6 \%$. Among these cells, $1.2 \pm 0.9 \%$ were neutrophils $\left(\mathrm{SSC}^{\mathrm{hi}} \mathrm{GR}-1^{+}\right), 26.2 \pm 18.6 \%$ were macrophages $\left(\mathrm{CD} 11 \mathrm{~b}^{+}\right.$ $\left.\mathrm{F} 4 / 80^{+}\right)$and $17.3 \pm 12.4 \%$ were myeloid DCs $\left(\mathrm{CD} 11 \mathrm{c}^{+}\right.$ 


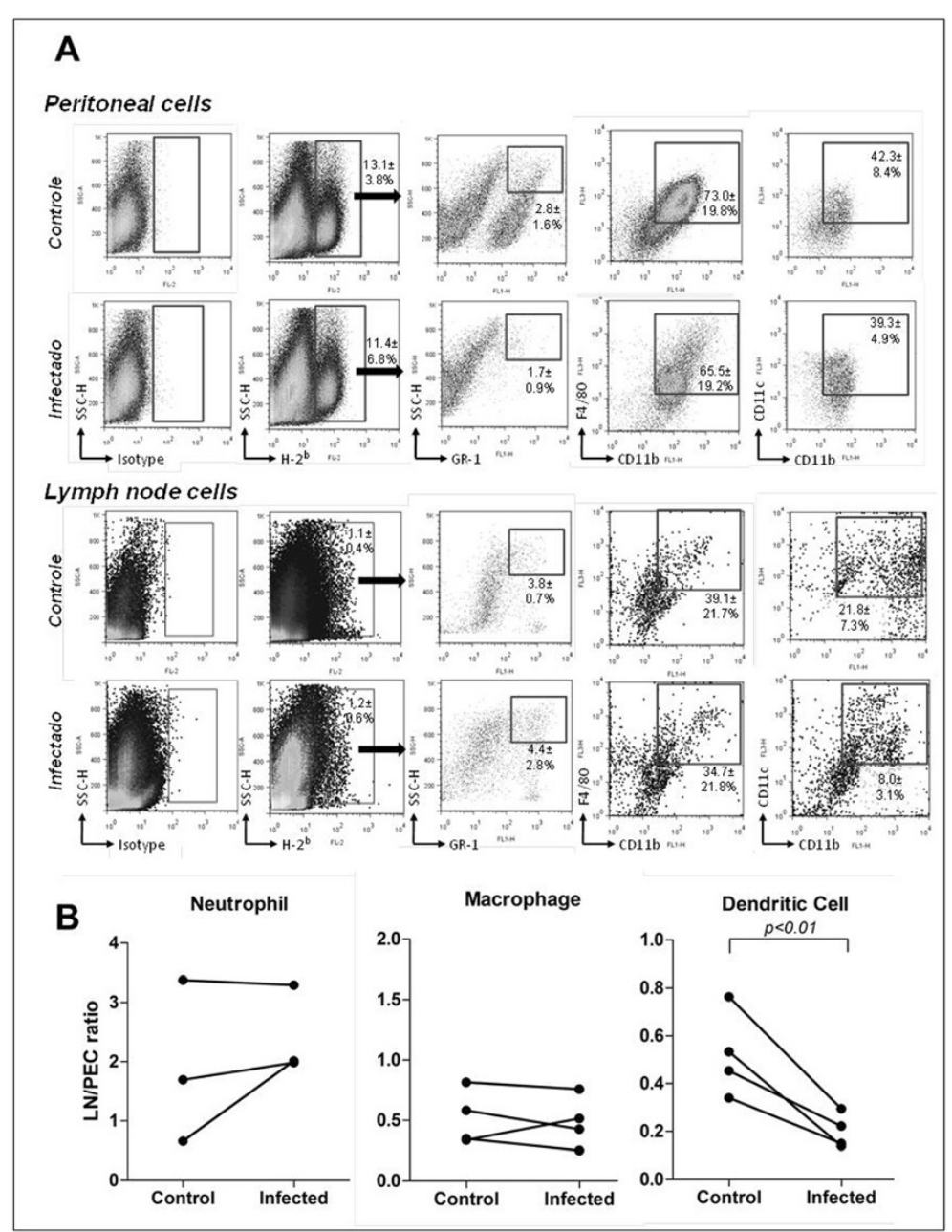

Figure 1 Phenotypic analysis of the in vivo cell transfer-and-tracking assay from C57BL/6 mice to BALB/c mice. Infected (L. amazonensis) or control (medium alone) thioglycollate-elicited peritoneal exudate cells (PEC) of C57BL/6 mice were injected i.p. in BALB/c mice previously stimulated with thioglycollate. After 24 hours, the PEC and draining thymic LNs were collected, and the $\mathrm{H}-2 \mathrm{~Kb}^{+}(\mathrm{C} 57 \mathrm{BL} / 6)$ cells were analyzed. The main phagocyte populations were defined by the expression of the indicated markers. (A) Dot plots from one representative experiment with values representing the mean $\pm s d$ of four experiments that were independently performed. (B) Comparison of the proportion of migrating phagocytes of different phenotypes from the inflammatory site to the draining $L N$ after incubation with medium alone (control) or with $L$. amazonensis (infected) (10 promastigotes per PEC). Each point represents the percentage of cells among the migrating leukocytes (injected into the peritoneal cavity and tracked to the $L N$ ) relative to the percentage of the same injected cell population remaining in the peritoneal cavity.

$\mathrm{CD}_{11 \mathrm{~b}^{+}}$) (Figure 2A). Again, only the proportion of migrating $\left(\right.$ Ly $\left.5.1^{+}\right)$myeloid DC populations was consistently decreased in the draining LN after co-incubation with Leishmania $\mathrm{t}$ Test, paired test, $\mathrm{P}<0.01$, Figure $2 \mathrm{~B}$.

\section{Discussion}

Our data showed a varied population of leukocytes in the peritoneum at 4 days after thioglycollate-induced peritonitis, with a predominance of cells with a monocyte/ macrophage morphology. These data confirm previous observations by Cook and colleagues [29] and were further supported by flow cytometry observations that most of these peritoneal cells had a CD11b ${ }^{\text {hi }}$ F $/ / 80^{\text {hi }}$ (macrophage) phenotype. The infection rate and phagocytosis of dead Leishmania were high among $\mathrm{CD}_{11 \mathrm{~b}^{+}}$myeloid cells and were similar between $\mathrm{CD}_{11 \mathrm{~b}^{+}} \mathrm{CD} 11 \mathrm{c}^{-}$(macrophage/

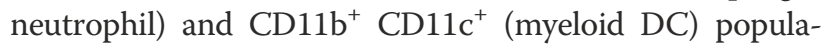
tions. In contrast, Leishmania infection/phagocytosis was

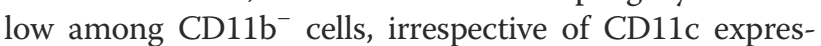

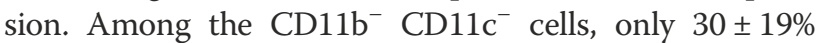
phagocytized the parasite, and this total may include resident peritoneal macrophages [29]. These data confirm the observations of Murielle and collaborators, who showed that $\mathrm{CD} 11 \mathrm{~b}^{+}$and $\mathrm{GR}-1^{+}$cells were the most frequently infected cells present in primary lesions produced by Leishmania major infection of the mice hypoderm [4]. Leon and collaborators also showed that both the macrophage $\left(\mathrm{CD} 11 \mathrm{~b}^{+} \mathrm{CD} 11 \mathrm{c}^{-}\right)$and the dermal monocyte-derived 


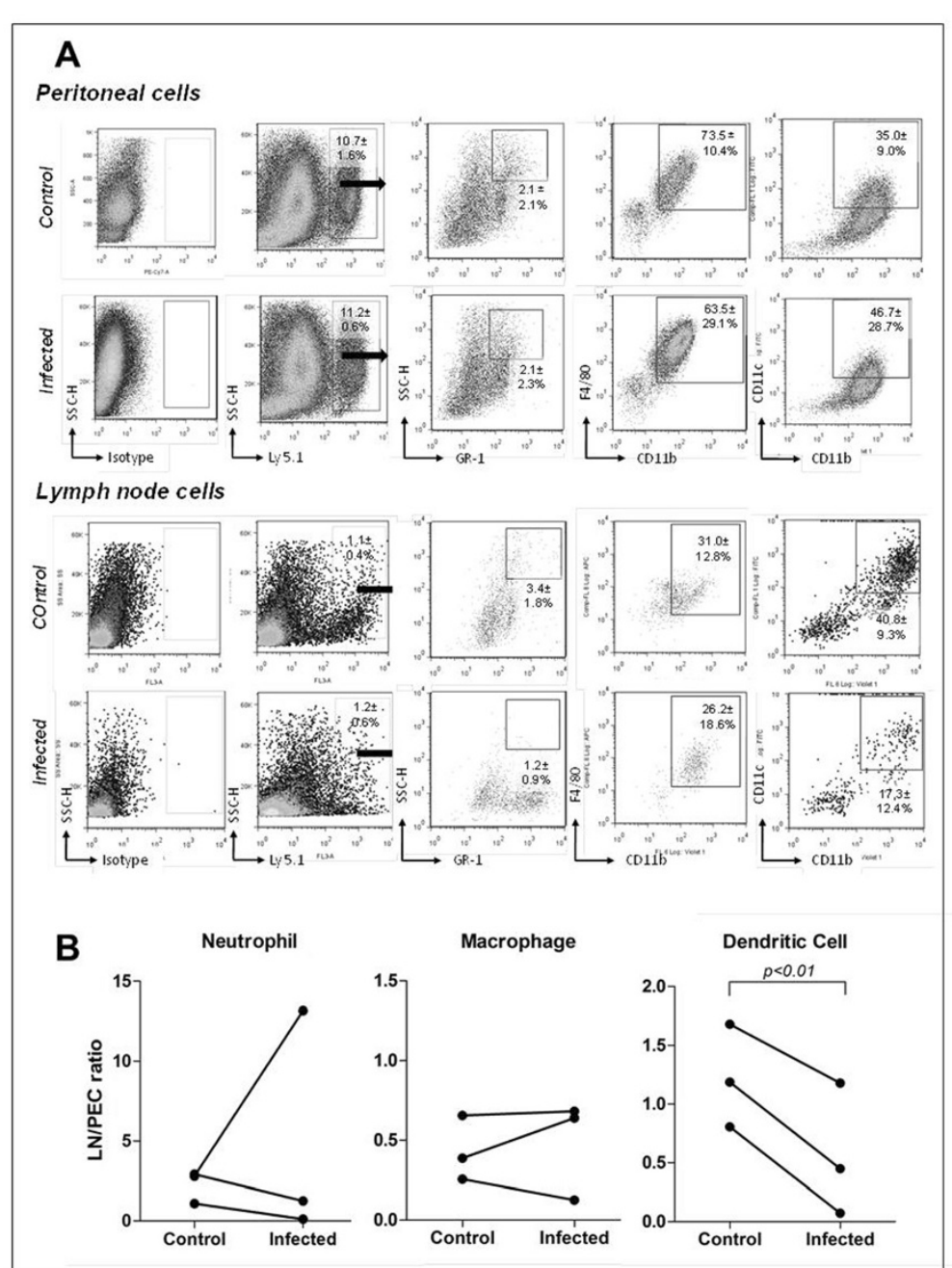

Figure 2 Phenotypic analysis of Ly5. $1^{+}$cells that migrated from the peritoneum to the LN after Leishmania infection. Infected (L. amazonensis) or control (medium alone) cells from C57BL/6 Ly5.1 $1^{+}$mice were injected i.p. into C57BL/6 Ly5.1 $1^{-}$mice previously stimulated with thioglycollate. After 24 hours, the LNs were collected and only Ly $5.1^{+}$cells were analyzed. The main phagocyte populations are defined by the expression of the indicated markers. (A) Dot plots from one representative experiment with values representing the mean $\pm s d$ of three experiments that were independently performed. (B) Comparison of the proportion of migrating phagocytes of different phenotypes from the inflammatory site to the draining LN after incubation with medium alone (control) or with L. amazonensis (infected) (10 promastigotes per PEC). Each point represents the percentage of cells among the migrating leukocytes (injected into the peritoneal cavity and tracked to the LN) relative to the percentage of the same injected cell population remaining in the peritoneal cavity.

dendritic cells $\left(\mathrm{CD} 11 \mathrm{~b}^{+} \mathrm{CD} 11 \mathrm{c}^{+}\right)$had the highest parasite burdens among the leukocytes found in the dermal-infiltrate after Leishmania infection in vivo [7]. In a previous study, we also showed that PEC with $\mathrm{CD} 11 \mathrm{~b}^{\text {hi }}$ expression presented the highest levels of Leishmania infection compared with the CD11b $\mathrm{b}^{\text {neg }}$ and CD11b ${ }^{\text {lo }}$ populations [12]. CD11b is the $\alpha M$ subunit of the integrin capable of mediating interactions of leukocytes with ICAM-1, the extracellular matrix proteins and the complement component iC3b. Therefore, CD11b expression by this myeloid cell population may enhance phagocytosis of opsonized parasites.
In a previous study, we observed that in vitro coincubation for 6-24 $\mathrm{h}$ with Leishmania decreases the adherence of the J774 cell line, human peripheral blood monocytes and thioglycollate-elicited inflammatory peritoneal exudate cells (PEC) to both connective tissue and connective matrix components, such as fibronectin. This decrease in phagocyte adhesion resulted from an impairment in integrin regulation rather than an inhibition of integrin expression. This decrease also correlated with the percentage of phagocytes containing amastigotes and with the parasite burden in the phagocytes to the extent that, with a $50 \%$ phagocyte infection rate and a parasite burden 
of 4 amastigotes per phagocyte, a $70 \%$ reduction in PEC adhesion to fibronectin was achieved $[8,12]$. In this study, we show that the coincubation of PEC with Leishmania in conditions that favor a high parasite burden also decrease phagocyte migration from an inflammatory site to the draining lymph node in vivo. Although a trend of a decrease in the migration rate of $\mathrm{F} 4 / 80^{+}$cells and of neutrophils was observed in some experiments, only the $\mathrm{CD} 11 \mathrm{c}^{+}$cell population presented a consistent decrease in migration in all experiments using the adoptive transfer of cells between C57BL/6 and BALB/c mice or between Ly5.1 $1^{+}$and Ly5.1 $1^{-}$animals.

Different dendritic cell subsets have been considered the leading transporters of antigens and pathogens from the periphery to the lymph nodes. For instance, Steigerwald and Moll showed that infecting DCs with L. major impaired their ability to migrate in response to a variety of chemokines, except to CCL21 [20]. This chemokine is produced by lymphatic endothelial cells and may be involved in leukocyte migration from the inflammatory site to lymph nodes. For instance, monocyte-derived DCs retained in the skin expressed less CCR7 (CCL21 receptor) than did uninfected monocyte-derived DCs that were capable of migrating to the draining lymph nodes [7]. However, Ato and collaborators found that DC migration into the lymphoid tissue of the spleen in L. donovaniinfected mice was impaired due to deficient CCR7 expression [30]. A possible explanation for these contradictory data is the differences in DC response to infection by different Leishmania species. Alternatively, DC populations may present intrinsically different responses to Leishmania infection. In our previous work, we have shown that the decrease in phagocyte adherence to connective tissue was independent on the species of Leishmania. Furthermore, the parasite burden was directly associated with the decrease in phagocyte adherence to the connective tissue [12]. In this study, we used 10 promastigotes per PEC. This parasite-leukocyte ratio allowed for a high parasite burden and a low level of phagocyte binding to the connective tissue or to isolated connective matrix components in adhesion assays [12]. Therefore, a high parasite burden may impair the migratory DC capability, as occurs with other phagocyte functions, in Leishmania-infected cells $[12,17,20]$. Such differences in migration patterns among DC subpopulations and between DC and other phagocyte populations after contact with Leishmania deserve further comparative studies using sorted cell populations.

Finally, this finding of the decrease in migration of DCs coincubated with Leishmania concurs with studies by Jebbari and colleagues and Leon and colleagues that showed the permanence of infected dendritic cells at the inoculation site $[7,31]$. The permanence of these infected cells at the infection site may be a determinant for the appearance of ulcers in tegumentary forms of leishmaniasis. The mechanisms associated with the development of skin lesions in cutaneous localized leishmaniasis are not completely understood. Evidence suggests that these ulcers develop at the site of parasite inoculation. Type IV cellular hypersensitivity may be involved, but in a considerable number of patients, it is not detected by the leishmanin skin test at the time of ulcer [32]. Recently, a subpopulation of DCs that has been implicated in maintaining the inflammatory status in tissues was evidenced in different diseases [33]. Hence, the study of the mechanisms controlling the migration of infected cells and the potential role of migrating and non-migrating DC in the development of lesions is important to understand the pathogenesis of inflammatory diseases.

\section{Conclusions}

Coincubation with Leishmania impair DC migration from the inflammatory site to the draining lymph node. Such changes in dendritic cell migration pattern may be associated with immunological events that maintain inflammation at the sites of infection.

\section{Abbreviations}

DC: Dendritic cell; PEC: Peritoneal exudate cells; VLA-4: Very Late Antigen-4; HBSS: Hanks' balanced salt solution; FBS: fetal bovine serum; RPMI: Roswell Park Memorial Institute; LNs: Lymph nodes.

\section{Competing interests}

The authors declare that they have no competing interests.

\section{Authors' contributions}

MDRH Conceived and designed the experiments of the study, performed the experiments and statistical, analysis the data and drafted the manuscript. PGD, AMPT participated in the cell transfer-and-tracking experiments. JOM participated in design of flow cytometer experiments. WLCS conceived of the study, and participated in its design and coordination and drafted the manuscript. All authors read and approved the final manuscript.

\section{Acknowledgements}

We thank Dr. Paul Kaye and the staff of the Centre for Immunology and Infection, University of York, for their help with the experiments using Ly 5.1 animals. This work was supported by the Brazilian Ministry of Science and Technology, Brazilian National Research Council - CNPq, grant no. 474548/2009-0.

\section{Author details}

${ }^{1}$ Centro de Pesquisas Gonçalo Moniz, Oswaldo Cruz Foundation, Fiocruz, LPBI, Salvador, Brazil. ${ }^{2}$ Instituto Oswaldo Cruz, Oswaldo Cruz Foundation, Fiocruz, Rio de Janeiro, Brazil. ${ }^{3}$ Faculty of Medicine of Petrópolis, FMP-FASE, Petrópolis, Brazil.

Received: 17 March 2014 Accepted: 13 August 2014

Published: 20 August 2014

\section{References}

1. Guarga JL, Lucientes J, Peribáñez MA, Molina R, Gracia MJ, Castillo JA: Experimental infection of Phlebotomus perniciosus and determination of the natural infection rates of Leishmania infantum in dogs. Acta Trop 2000, 77:203-207.

2. Liew FY, O'Donnell CA: Immunology of leishmaniasis. Adv Parasitol 1993, 32:161-259.

3. Moll H, Fuchs H, Blank C, Röllinghoff M: Langerhans cells transport Leishmania major from the infected skin to the draining lymph node for presentation to antigen-specific T cells. Eur J Immunol 1993, 23:1595-1601. 
4. Muraille E, De Trez C, Pajak B, Torrentera FA, De Baetselier P, Leo O, Carlier Y: Amastigote load and cell surface phenotype of infected cells from lesions and lymph nodes of susceptible and resistant mice infected with leishmania major. Infect Immun 2003, 71:2704-2715.

5. Peters NC, Kimblin N, Secundino N, Kamhawi S, Lawyer P, Sacks DL: Vector transmission of leishmania abrogates vaccine-induced protective immunity. PLOS Pathog 2009, 5:e1000484.

6. Ribeiro JM: Role of saliva in blood-feeding by arthropods. Annu Rev Entomol 1987, 32:463-478.

7. León B, López-Bravo M, Ardavín C: Monocyte-derived dendritic cells formed at the infection site control the induction of protective T helper 1 responses against Leishmania. Immunity 2007, 26:519-531.

8. Lemos de Souza V, Ascenção Souza J, Correia Silva TM, Sampaio Tavares Veras $P$, Rodrigues de-Freitas LA: Different Leishmania species determine distinct profiles of immune and histopathological responses in CBA mice. Microbes Infect 2000, 2:1807-1815

9. Veress B, Omer A, Satir AA, Hassan El AM: Morphology of the spleen and lymph nodes in fatal visceral leishmaniasis. Immunology 1977, 33:605-610.

10. Hume DA: The mononuclear phagocyte system. Curr Opin Immunol 2006 18:49-53.

11. Carvalhal DGF, Barbosa A Jr, D'El-Rei Hermida M, Clarencio J, Pinheiro NF Jr, Veras PST, Dos-Santos WLC: The modelling of mononuclear phagocyteconnective tissue adhesion in vitro: application to disclose a specific inhibitory effect of Leishmania infection. Exp Parasitol 2004, 107:189-199.

12. Pinheiro NF, Hermida MDR, Macedo MP, Mengel J, Bafica A, dos-Santos WLC: Leishmania Infection Impairs 1-Integrin Function and Chemokine Receptor Expression in Mononuclear Phagocytes. Infect Immun 2006, 74:3912-3921.

13. Sozzani S, Sallusto F, Luini W, Zhou D, Piemonti L, Allavena P, Van Damme J, Valitutti S, Lanzavecchia A, Mantovani A: Migration of dendritic cells in response to formyl peptides, $\mathrm{C} 5 \mathrm{a}$, and a distinct set of chemokines. $\mathrm{J}$ Immunol 1995, 155:3292-3295.

14. Randolph GJ, Angeli V, Swartz MA: Dendritic-cell trafficking to lymph nodes through lymphatic vessels. Nat Rev Immunol 2005, 5:617-628.

15. Palframan RT, Jung $S$, Cheng G, Weninger W, Luo Y, Dorf M, Littman DR, Rollins BJ, Zweerink H, Rot A, Andrian von UH: Inflammatory chemokine transport and presentation in HEV: a remote control mechanism for monocyte recruitment to lymph nodes in inflamed tissues. J Exp Med 2001, 194:1361-1373.

16. Janatpour MJ, Hudak S, Sathe M, Sedgwick JD, McEvoy LM: Tumor necrosis factor-dependent segmental control of MIG expression by high endothelial venules in inflamed lymph nodes regulates monocyte recruitment. J Exp Med 2001, 194:1375-1384.

17. Leon B, Ardavin C: Monocyte migration to inflamed skin and lymph nodes is differentially controlled by L-selectin and PSGL-1. Blood 2008, 111:3126-3130.

18. Warnock RA, Askari S, Butcher EC, Andrian von UH: Molecular mechanisms of lymphocyte homing to peripheral lymph nodes. J Exp Med 1998, 187:205-216.

19. Bellingan GJ, Caldwell H, Howie SE, Dransfield I, Haslett C: In vivo fate of the inflammatory macrophage during the resolution of inflammation: inflammatory macrophages do not die locally, but emigrate to the draining lymph nodes. J Immunol 1996, 157:2577-2585.

20. Steigerwald M, Moll H: Leishmania major modulates chemokine and chemokine receptor expression by dendritic cells and affects their migratory capacity. Infect Immun 2005, 73:2564-2567.

21. Wu Q, Feng Y, Yang Y, Jingliu, Zhou W, He P, Zhou R, Li X, Zou J: Kinetics of the phenotype and function of murine peritoneal macrophages following acute inflammation. Cell Mol Immunol 2004, 1:57-62.

22. Turchyn LR, Baginski TJ, Renkiewicz RR, Lesch CA, Mobley JL: Phenotypic and functional analysis of murine resident and induced peritoneal macrophages. Comp Med 2007, 57:574-580

23. Barral A, Pedral-Sampaio D, Grimaldi Júnior G, Momen $H$, McMahon-Pratt D, Ribeiro de Jesus A, Almeida R, Badaro R, Barral-Netto M, Carvalho EM: Leishmaniasis in Bahia, Brazil: evidence that Leishmania amazonensis produces a wide spectrum of clinical disease. Am J Trop Med Hyg 1991 44:536-546.

24. Saldanha Machado CJ, Tereza A, Filipecki P, Teixeira M: Current Brazilian law on animal experimentation. Science 2009, 324:1643-1644.

25. Nibbering PH, Leijh PC, van Furth R: Quantitative immunocytochemical characterization of mononuclear phagocytes. II. Monocytes and tissue macrophages. Immunology 1987, 62:171-176.
26. Lagasse $E$, Weissman IL: Flow cytometric identification of murine neutrophils and monocytes. J Immunol Methods 1996, 197:139-150.

27. $\mathrm{Wu}$ L, Li CL, Shortman K: Thymic dendritic cell precursors: relationship to the $T$ lymphocyte lineage and phenotype of the dendritic cell progeny. J Exp Med 1996, 184:903-911

28. Pulendran B, Smith JL, Caspary G, Brasel K, Pettit D, Maraskovsky E, Maliszewski CR: Distinct dendritic cell subsets differentially regulate the class of immune response in vivo. Proc Natl Acad Sci U S A 1999, 96:1036-1041

29. Cook AD, Braine EL, Hamilton JA: The phenotype of inflammatory macrophages is stimulus dependent: implications for the nature of the inflammatory response. J Immunol 2003, 171:4816-4823.

30. Ato M, Stäger S, Engwerda CR, Kaye PM: Defective CCR7 expression on dendritic cells contributes to the development of visceral leishmaniasis Nat Immunol 2002, 3:1185-1191.

31. Jebbari H: Leishmania major promastigotes inhibit dendritic cell motility in vitro. Infect Immun 2002, 70:1023-1026.

32. Manson-Bahr PE: Immunity in kala-azar. Trans R Soc Trop Med Hyg 1961 , 55:550-555

33. Yen JH, Kong W, Ganea D: IFN- inhibits dendritic cell migration through STAT-1-mediated transcriptional suppression of CCR7 and matrix metalloproteinase 9. J Immunol 2010, 184:3478-3486.

doi:10.1186/1471-2334-14-450

Cite this article as: Hermida et al:: Leishmania amazonensis infection impairs dendritic cell migration from the inflammatory site to the draining lymph node. BMC Infectious Diseases 2014 14:450.

\section{Submit your next manuscript to BioMed Central and take full advantage of:}

- Convenient online submission

- Thorough peer review

- No space constraints or color figure charges

- Immediate publication on acceptance

- Inclusion in PubMed, CAS, Scopus and Google Scholar

- Research which is freely available for redistribution

Submit your manuscript at www.biomedcentral.com/submit
C Biomed Central 